\title{
Synthesis of (2-pyridyl)-Acetyl Chitosan and Its Antioxidant Activity
}

\author{
Rong-chun Li* \\ Department of Chemistry, Dezhou University, Dezhou 253023, China. "E-mail: lirc78@126.com
}

(Received March 31, 2011; Accepted Juny 8, 2011)

\begin{abstract}
In this paper, chloracetyl chitosan (CACTS) was prepared at first. In the molecules of CACTS, there are active chlorine groups, which can take part in other reactions. Thus, number of chitosan derivatives will be obtained after chlorine is substituted. Choosing pyridine as the active group, a novel water-soluble chitosan derivative, (2-pyridyl)-acetyl chitosan (PACTS) was obtained and its antioxidant activity against hydroxyl radicals and superoxide radicals was assessed. The results indicated that PACTS had better antioxidant activity than that of chitosan, carboxymethyl chitosan (CMCTS), hydroxypropyl chitosan (HPCTS), and Vitamin C. And the $\mathrm{IC}_{50}$ values against hydroxyl radicals and superoxide radicals were $0.31 \mathrm{mg} / \mathrm{mL}$ and $0.21 \mathrm{mg} / \mathrm{mL}$, respectively.
\end{abstract}

Key words: synthesis, (2-pyridyl)-acetyl chitosan, antioxidant activity

\section{INTRODUCTION}

As a non-toxic, biocompatible and biodegradable polymer, chitosan has attracted much attention for its unique biological activities. ${ }^{1-7}$ However, the application of chitosan is limited because of its poor solubility in water or high $\mathrm{pH}$ region. So it is important to improve the soluble property of chitosan. In order to increase the solubility, many derivatives have been synthesized such as hydroxypropyl chitosan (HPCTS), carboxymethyl chitosan (CMCTS) and so on. ${ }^{8}$ In this paper, a novel water-soluble chitosan derivative, (2-pyridyl)-acetyl chitosan (PACTS) was synthesized.

It has been found that chitosan has antioxidant activity, and that, many chitosan derivatives were synthesized and their antioxidant activity was assessed accordingly. ${ }^{8-10}$ Among various reactive oxygen species, both of hydroxyl radical and superoxide radical have strong chemical activity, which can damage a wide range of essential biomolecules such as amino acids, proteins, and DNA. ${ }^{11}$ In this paper, the antioxidant activity against hydroxyl radicals and superoxide radicals of PACTS were estimated.

\section{EXPERIMENTAL}

Chitosan was purchased from Qingdao Baicheng biochemical Corp. (China). The degree of deacetylation was $97 \%$ and the viscosity average-molecular weight was 7.0 $\times 10^{4}$. The other reagents were all analytical grade and used without further purification.

The derivatives were synthesized based on the earlier method (Fig. 1): ${ }^{12}$

CACTS, $1.61 \mathrm{~g}$ chitosan was dispersed in $100 \mathrm{~mL} \mathrm{N-}$ methyl-2-pyrrolidone (NMP) and stirred for $12 \mathrm{~h}$ at room temperature $(\mathrm{r}$ t). Then $0.02 \mathrm{~mol}$ chloracetyl chloride was added. After stirring for $24 \mathrm{~h}$ at $\mathrm{r} \mathrm{t}$, the solution was precipitated in ether and the precipitate was washed with methanol and ether by turns and lyophilized and CACTS was obtained.

PACTS, $0.2 \mathrm{~g}$ CACTS was dissolved into $10 \mathrm{~mL}$ of dimethyl sulfoxide (DMSO) at $60{ }^{\circ} \mathrm{C}$ and $0.5 \mathrm{~mL}$ pyridine was added with stirring for $20 \mathrm{~h}$. The solution was collected by precipitation with excess acetone. After drying at $60{ }^{\circ} \mathrm{C}$ for $24 \mathrm{~h}$, PACTS was obtained in $87 \%$ yield (The yield is based on the ratio of PACTS and added chitosan).

CMCTS and HPCTS were synthesized according to the method of Xie. ${ }^{13}$

The antioxidant activity against hydroxyl radicals was carried out according to Guo. ${ }^{14}$ The reaction mixture, total volume $4.5 \mathrm{~mL}$, containing the samples of chitosan derivatives, was incubated with EDTA-Fe ${ }^{2+}(220 \mu \mathrm{M})$, safranine $\mathrm{O}(0.23 \mu \mathrm{M}), \mathrm{H}_{2} \mathrm{O}_{2}(60 \mathrm{iM})$ in potassium phosphate buffer (150 mM, pH 7.4) for $30 \mathrm{~min}$ at $37^{\circ} \mathrm{C}$. The absorbance of the mixture was measured at $520 \mathrm{~nm}$. Hydroxyl radicals

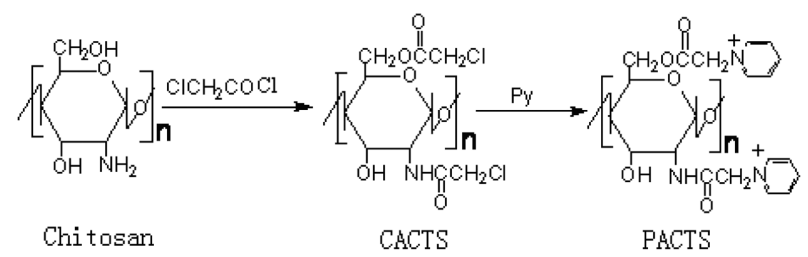

Figure 1. Synthetic pathway of PACTS. 
bleached the safranine $\mathrm{O}$, so decreased absorbance of the reaction mixture indicated decreased hydroxyl radicals scavenging ability (equation 1).

Scavenging effect (\%)

$$
\begin{aligned}
& {\left[\left(A_{\text {sample } 520 \mathrm{~nm}}-A_{\text {blank } 520 \mathrm{~nm}}\right) /\left(A_{\text {control } 520 \mathrm{~nm}}-A_{\text {blank } 520 \mathrm{~nm}}\right)\right]} \\
& \quad \times 100
\end{aligned}
$$

Where $A_{\text {blank } 520 n m}$ is the absorbance of the blank (distilled water, instead of the samples) and $A_{\text {control } 520 n m}$ is the absorbance of the control (distilled water, instead of $\mathrm{H}_{2} \mathrm{O}_{2}$ ).

The scavenging of superoxide radicals was carried out according to an earlier method. ${ }^{15}$ Different concentrations of each derivatives of chitosan were mixed separately with PMS $(30 \mu \mathrm{M})$, NADH $(338 \mu \mathrm{M})$, and NBT $(72 \mu \mathrm{M})$ in Tris- $\mathrm{HCl}(16 \mathrm{mM}, \mathrm{pH} 8.0)$ and then incubated at room temperature for $5 \mathrm{~min}$. The absorbance was measured and the capability of scavenging superoxide radicals was calculated using the following equation (2):

Scavenging effect (\%)

$$
\left(1-A_{\text {sample } 520 \mathrm{~nm}} / A_{\text {control } 520 \mathrm{~nm}}\right) \times 100
$$

Where $A_{\text {control } 560 \mathrm{~nm}}$ is the absorbance of the control (Tris$\mathrm{HCl}$ buffer, instead of NADH).

\section{Results and Discussion}

The IR spectra data of chitosan, CACTS and PACTS are shown in Figure 2. The IR spectra data of chitosan shows peaks assigned to the saccharine structure at 895 and 1155 $\mathrm{cm}^{-1}$ and amino characteristic peaks at around $1600 \mathrm{~cm}^{-1}$.

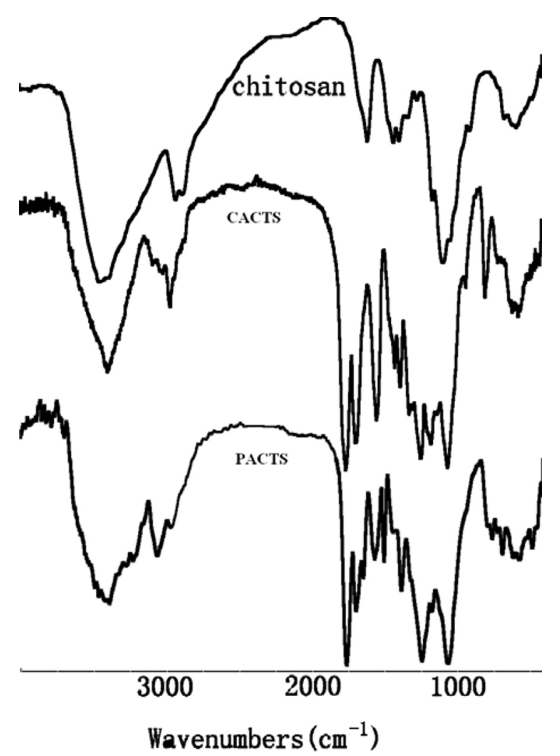

Figure 2. IR spectra data of chitosan, CACTS and PACTS.

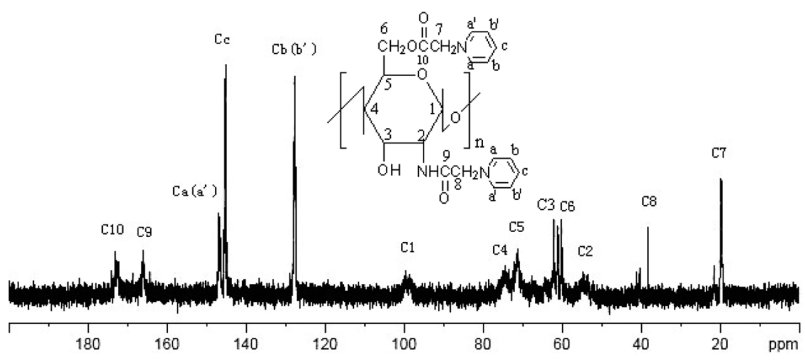

Figure 3. ${ }^{13} \mathrm{C}$ NMR spectra of PACTS.

For CACTS, there are strong peaks at 1749, 1682 and 790 $\mathrm{cm}^{-1}$, attributed to groups of carbonyl and $\mathrm{C}-\mathrm{Cl},{ }^{16}$ which indicates that CACTS was synthesized. For PACTS, there are peaks at 1492, 1640 and $3056 \mathrm{~cm}^{-1}$, attributed to the characteristic absorbance of pyridine. ${ }^{17}$ The characteristic absorb of C-Cl groups at $790 \mathrm{~cm}^{-1}$ disappeared after pyridine was grafted.

Figure 3 presented the ${ }^{13} \mathrm{C}$ NMR of PACTS. In the ${ }^{13} \mathrm{C}$ NMR spectra of PACTS, the chitosan backbone signals can be seen at $99.7 \mathrm{ppm}\left(\mathrm{C}_{1}\right), 74.5 \mathrm{ppm}\left(\mathrm{C}_{4}\right), 71.3 \mathrm{ppm}$ $\left(\mathrm{C}_{5}\right), 62.2 \mathrm{ppm}\left(\mathrm{C}_{3}\right), 60.2 \mathrm{ppm}\left(\mathrm{C}_{6}\right), 55.8 \mathrm{ppm}\left(\mathrm{C}_{2}\right) .{ }^{18}$ Also the graft evidences are clear. The peaks at $173.1 \mathrm{ppm}$ and $166.9 \mathrm{ppm}$ are corresponded to carbonyl groups. ${ }^{17}$ The strong peaks at $146.8 \mathrm{ppm}, 145.5 \mathrm{ppm}, 127.8 \mathrm{ppm}$ are corresponded to pyridine ring carbons. ${ }^{19}$ The peaks at $20.0 \mathrm{ppm}$ and $39.5 \mathrm{ppm}$ can be assigned for methylene carbons. ${ }^{18}$ Above ${ }^{13} \mathrm{C}$ NMR results further confirmed that PACTS was obtained.

The hydroxyl radicals, generated by the Fenton reaction in this system, was scavenged by chitosan, chitosan derivatives and Vitamin C. Figure 4 shows that the scavenging effect of all the samples raised with the increases

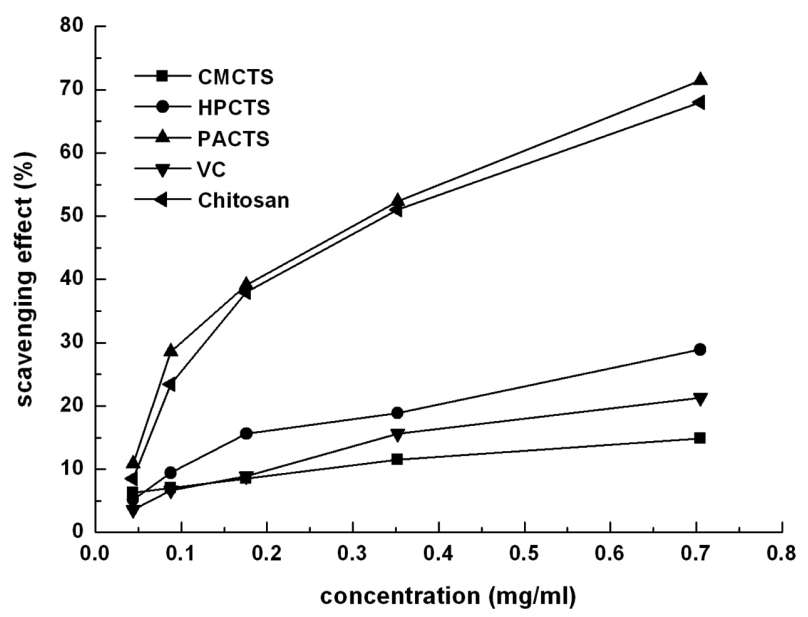

Figure 4. Scavenging effect of chitosan, chitosan derivatives and Vitamin $\mathrm{C}$ on hydroxyl radicals. 

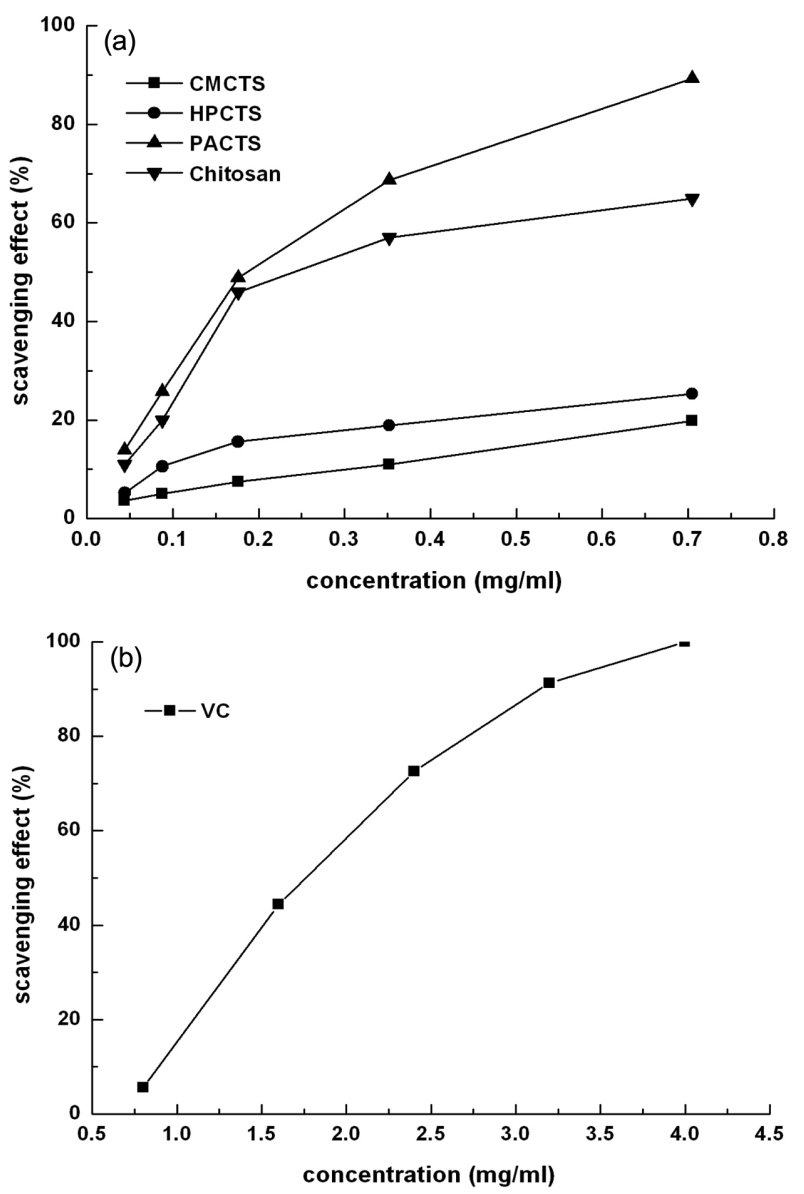

Figure 5. (a) Scavenging effect of chitosan, chitosan derivatives on superoxide radicals Values are mean $\pm \mathrm{SD}(\mathrm{n}=3)$. (b) Scavenging effect of $\mathrm{VC}$ on superoxide radicals Values are mean \pm SD $(n=3)$.

of concentration. Among all the chitosan derivatives and Vitamin C, PACTS has the best scavenging effect against hydroxyl and the $\%$ scavenging effect is 71.5 at $0.71 \mathrm{mg} / \mathrm{mL}$. Much attention has been put on CMCTS and HPCTS because of their good water-solubility. But, the antioxidant activity of these two compounds against hydroxyl radicals is very soft, and the scavenging effect is $14.9 \%$ and $28.9 \%$, respectively, at $0.71 \mathrm{mg} / \mathrm{mL}$. Compared with Vitamin C, CMCTS and HPCTS have similar scavenging effect and they all have poorer activity than chitosan. However, PACTS has better activity at tested concentration and the $\mathrm{IC}_{50}$ was determined to be $0.31 \mathrm{mg} / \mathrm{mL}$.

Figure 5(a) shows the inhibitory effect of chitosan, CMCTS, HPCTS, and PACTS against superoxide radicals. All derivatives have inhibitory ability against superoxide radicals, and the activity is affected by the concentration. It is obvious that PACTS has better scavenging effect than that of chitosan, CMCTS and HPCTS at all the tested con- centrations, and the $\mathrm{IC}_{50}$ of PACTS was determined to be $0.21 \mathrm{mg} / \mathrm{mL}$. However, $\mathrm{IC}_{50}$ of CMCTS and HPCTS can not be read at the tested concentration. Figure 5(b) shows the superoxide radicals scavenging ability of Vitamin $\mathrm{C}$, and the $\mathrm{IC}_{50}$ is $1.7 \mathrm{mg} / \mathrm{mL}$.

\section{Conclusion}

As shown in Scheme I, CACTS has similar structure with chitin and it can not dissolved in water at any $\mathrm{pH}$. In the molecules of CACTS, there are active chlorine groups, which can take part in other reactions. Thus, number of chitosan derivatives will be obtained after chlorine is substituted. Choose pyridine as the active groups and one novel water-soluble chitosan derivative, PACTS is obtained. Compared with the other two water-soluble derivatives of chitosan - CMCTS and HPCTS, PACTS has better antioxidant activity against hydroxyl radicals and superoxide radicals. Further study about this kind of chitosan derivatives and similar compounds is necessary.

Acknowledgements. This work was supported by key technology research and development programme of Shandong Province (2007GG2QT06020). Thanks for the financial support by the foundation of national natural science (21046003). Thanks for the financial support by the foundation of national natural science (20774011). Thanks for the financial support by the talent introduction programme of Dezhou University (402110).

\section{REFERENCES}

1. Muzzarelli, R. A. A. Anal. Chem. Acta 1971, 54, 133.

2. Kurita, K. Prog. Polym. Sci. 2001, 26, 1921.

3. Lim, S. H.; Hudson, S. M. Carbohydr. Res. 2004, 339, 313.

4. Kim, K. W.; Thomas, R. L. Food. Chem. 2007, 101, 308.

5. Avadi, M. R.; Sadeghi, A. M. M.; Tahzibi, A.; Bayati, K.; Pouladzadeh, M. M.; Zohuriaan-Mehr, J.; Rafiee-Tehrani, M. Europ. Polym. J. 2004, 40, 1355.

6. El-Ghaouth, A.; Smilanick, J. L.; Wilson, C. L. Postharvest. Biolog. Technol. 2000, 19, 103.

7. Guo, Z. Y.; Xing, R. E.; Liu, S.; Yu, H. H.; Wang, P. B.; Li, C. P.; Li, P. C. Bioorg. Med. Chem. Lett. 2005, 15, 4600.

8. Xing, R. E.; Yu, H. H.; Liu, S.; Zhang, W. W.; Zhang, Q. B.; Li, Z. E.; Li, P. C. Bioorg. Med. Chem. 2005, 13, 1387.

9. Xie, W. M.; Xu, P. X.; Liu, Q. Bioorg. Med. Chem. Lett. 2001, 11, 1699.

10. Esumi, K.; Takei, N.; Yoshimura, T. Colloids. Surf. B. 
2003, 32, 117.

11. Halliwell, B.; Gutteridge, J. M. C. Methods Enzymol. 1990, 86, 1.

12. Li, R.; Guo, Z.; Jiang, P. Carbohydr. Res. 2010, 345 , 1896.

13. Xie, W. M.; Xu, P. X.; Wang, W.; Liu, Q. Carbohydr. Polym. 2002, 50, 35.

14. Guo, Z.; Liu, H.; Chen, X.; Ji, X.; Li, P. Bioorg. Med. Chem. Lett. 2006, 16, 6348.
15. Nishimiki, M.; Rao, N. A.; Yagi, K. Biochem. Biophys. Res. Commun. 1972, 46, 849.

16. Baumann, H.; Faust, V. Carbohydr. Res. 2001, 331, 43.

17. Panicker, C. Y.; Varghese, H. T.; Philip, D.; Nogueira, H. I. S. Spectrochim Acta, Part A. 2006, 64, 744.

18. Heras, A.; Rodríguez, N. M.; Ramos, V. M.; Agulló, E. Carbohydr. Polym. 2001, 44, 1.

19. Chruszcz, K.; Barañska. M.; Czarniecki, K.; Boduszek, B.; Proniewicz, L. M. J. Mol. Struc. 2003, 648, 215. 